\title{
TRACK GAUGE STABILITY UNDER EFFECT OF SLEEPER THERMAL EXPANSION
}

\author{
VÍT LoJdA*, HANA KREJČǏ̌íKOVÁ \\ Czech Technical University in Prague, Faculty of Civil Engineering, Department of Railway Structures, \\ Thákurova 7, 16629 Prague, Czech Republic \\ * corresponding author: vit.lojda@fsv.cvut.cz
}

Abstract. Railway sleepers are traditionally made of hardwood, pre-stressed concrete or steel. However, emerging advanced materials, including polymers or composites, are investigated for a possible employment in the sleeper production. The main function of sleepers is to distribute forces they carry onto the trackbed, to support rails and keep the spacing between them, called the track gauge. The operating tolerance of the track gauge is critical for safety and is set by regulations. Generally, it is advisable to keep the track gauge deviation, as well as the sleeper length deviation influencing it, as low as reasonably practicable. In this article, the recommended limit values of the thermal expansion coefficient characterizing possible sleeper length deviation were evaluated. The recommendation considered allowed track gauge tolerance and the experimentally determined temperatures of a sleeper measured in the trackbed for a year. In addition, thermal expansion of a selected polymer in laboratory conditions was determined, representing an alternative material for the sleeper production. Consequently, it was compared with the limit and conservatively used materials. Furthermore, the same tested polymer, but utilizing chopped glass fibres to reduce the thermal expansion of the polymer, was also tested. Results show a positive impact of the glass reinforcement on the thermal expansion coefficient. The applicability of the selected polymer in the railway sleeper production from the perspective of the thermal expansion was discussed in the paper.

KEYWORDS: Sleeper, polymer, track gauge, thermal expansion.

\section{INTRODUCTION}

Railway sleepers are beams supporting rails (Figure 1). Sleepers are laid in railway ballast material up to their upper surface. Sleepers keep track gauge, carry vertical, longitudinal, and transversal forces, and distribute them to the ballast as described by Bonnet et al. [1].

As pointed out by Manalo et al. 22, railway sleepers can be classified as traditional (made of hard wood, pre-stressed concrete or steel) and alternative (made of polymers, composites with a polymer matrix, etc.). From the perspective of applicable properties, each mentioned material option may provide advantages for different specific track sections including straight or curved tracks, switches, bridges, railroad crossings, welded or non-welded rail. As reviewed by Ferdous, specific material limits, failure mechanisms and remedies should be taken into account for each material option [3].

Railway sleepers made of hard wood were the only material solution introduced at the beginning of railway transport in the $19^{\text {th }}$ century. These have provided sufficient stiffness, compressive and bending strength, and adaptability in the installation of a fastening system. On the downside, wood has a wellknown propensity for degradation by wood-destroying insects and fungi and, additionally, wide and longitudinal cracks occurring in wooden sleepers decrease their performance and ability to hold fasteners. These were

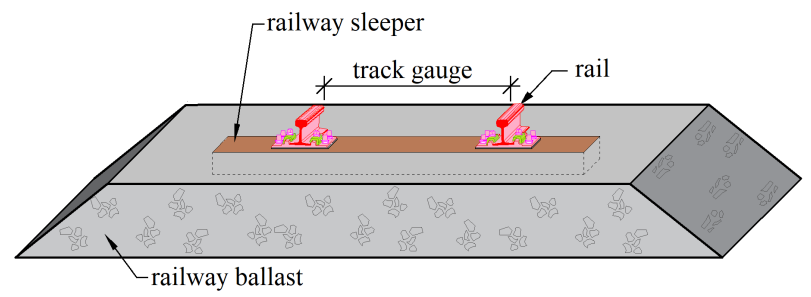

Figure 1. Railway sleeper laid in railway ballast.

partially solved by using creosote tar for preservation of the wood and by employment of condition monitoring methods simplifying the inspection of sleepers [4]. However, the creosote tar is considerably hazardous with respect to pollution of groundwater, and of air when burned, and its use was, therefore, regulated by the European Union - leading to a total ban of creosote (with few exceptions) in new or reconstructed railway lines after 2020 [5, 6]. Taking this into account, development of a safer preservation substance or an introduction of a material for the production of railway sleepers has become a new challenge of transportation engineering. Moreover, the lack of good-quality hard wood for the production of wooden sleepers led to the investigation of pre-stressed concrete has become available since mid of $20^{\text {th }}$ century.

Pre-stressed concrete became an attractive material providing high compressive strength and stability, both improving the capabilities of continuous welded 
rail, along with a high resistance to damage, adding to its superiority in service life. However, the higher stiffness of pre-stressed concrete results in sleepers with low damping coefficient and insufficient flexibility, which in turn leads to cracking in their midspan. Heavy loading and repeated dynamic load cycles, together with a relatively high rigidity of concrete surface, lead to excessive wear of trackbed [7. Consequently, the modification of contact parameters between sleeper soffit and grains, turn into a change in the granulometric curve producing fines leading to the deterioration of the railway ballast elasticity and permeability [8]. Finally, a track maintenance intervention is required.

As for pre-stressed concrete, an analogous case of the widespread expansion of a new sleeper material is the application of polymers or composite materials with a polymer matrix in the beginning of the $21^{\text {st }}$ century. After discovering the pultrusion process, first sleepers made of polyurethane foam and longitudinal glass fibres were introduced. Such sleepers were produced in Japan and installed on high speed railway tracks. This resemblance is based on the fact that it was necessary to develop the proper manufacturing technology and not only to develop a polymer, which had become common in industry about 100 years ago $\left[9\right.$. In the late $20^{\text {th }}$ century, the ever increasing consumption of polymer across industries, which volumetrically surpassed the amount of produced steel, glass or concrete, led to considerations about the treatment of polymer waste. The phenomenon of processing recycled polymers, especially by extrusion or moulding processes, enabled their use as secondary material for the transportation building industry, including railway structures. They are applied in the production of polymer railway sleepers, polymer sleeper anchors, damping mats or rail noise absorbers [10.

The use of recycled polymers in the production of railway sleepers brings advantages, including the assumed service life of up to 50 years, no biodegradability (and thus no need to use preservation substances), shape variability and design freedom, low weight benefitting the transportation and installation costs, and also the possibility to reduce wood consumption [11. Polymer sleepers are more flexible, and thus their application in switches and lines on undermined areas is beneficial [12. Since the application of creosote oil in wooden sleepers is to be banned, polymers can become the appropriate alternative of wood. Advanced and innovative application of polymers, composites with polymer matrix or sandwiches in the sleeper development can be found, for example, in [13, 14]. The recent developed polymer and composite sleeper types are summarized in Ferdous et al. [15. The crucial laboratory tests of plastic sleepers, which determine the material, application and supplementary properties including an issue of thermal expansion, were summarized by Lojda in [16, 17]. The characteristic of polymers is their sensitivity to the temperature influencing their properties 18. The thermal expansion of polymers is by an order of magnitude higher than of traditional materials [19].

The main objective of this article is to describe the role of the thermal expansion, represented by a coefficient of linear thermal expansion $\alpha$, in the development of polymer railway sleepers and to consider the range of $\alpha$ with respect to their production. Then, the coefficient $\alpha$ was experimentally determined on selected recycled polymer and composite specimens. The selected materials were subjected to temperature test cycles while the dimensions of specimens were measured. Taking the thermal expansion into account, the influence on the track gauge and possible production of railway sleepers was assessed. In addition, a recommendation of a limit value of the coefficient $\alpha$ for the material intended for the production of railway sleepers was proposed.

\section{DETERMINATION OF SLEEPER THERMAL EXPANSION}

A tendency of materials to change their volume upon change in temperature is referred to as the thermal expansion. Positive thermal expansion within polymers results in a volume increase if the material is heated and a decrease if cooled. In solids, this rate is characterized by the coefficient of linear thermal expansion $\alpha$ [20] expressed in Eq. (1):

$$
\alpha=\Delta l /\left(l_{0} \Delta T\right)
$$

where $\alpha$ is the coefficient of linear thermal expansion of the sleeper material $\left[\mathrm{K}^{-1}\right], \Delta l$ is the change in length $[\mathrm{mm}] ; l_{0}$ is the initial length $[\mathrm{mm}], \Delta T$ is the change in the sleeper's temperature $\left[{ }^{\circ} \mathrm{C}\right]$.

\subsection{EFFECT OF LINEAR THERMAL COEFFICIENT TO RAILWAY SLEEPERS}

The track gauge is defined as the distance measured in the direction perpendicular to the rail between the running edges of rails at a depth of $14 \mathrm{~mm}$ below the line that is bounded by the tops of the rail as described in the technical standard 736360-2 of Czech Office for Standards Metrology and Testing [21]. In the case that the coefficient $\alpha$ of the sleeper material, together with the change in the sleeper temperature $\Delta T$, would be substantially high, the track gauge may become affected. The change in the temperature $\Delta T$ is given as a difference between the temperature $T 1$ and temperature $T 2$. It is assumed that the rails are connected to a sleeper in the railway ballast at a temperature of $T 1$. As the sleeper is heated or cooled, depending on ambient temperature, the sleeper temperature changes to $T 2$ and based on the coefficient $\alpha$, the sleeper changes in its volume.

The dimensions of a typical sleeper are $2.60 \times 0.15 \times$ $0.26 \mathrm{~m}$ [22]. Since the length is about 10 times higher than the two remaining dimensions, the sleeper is 


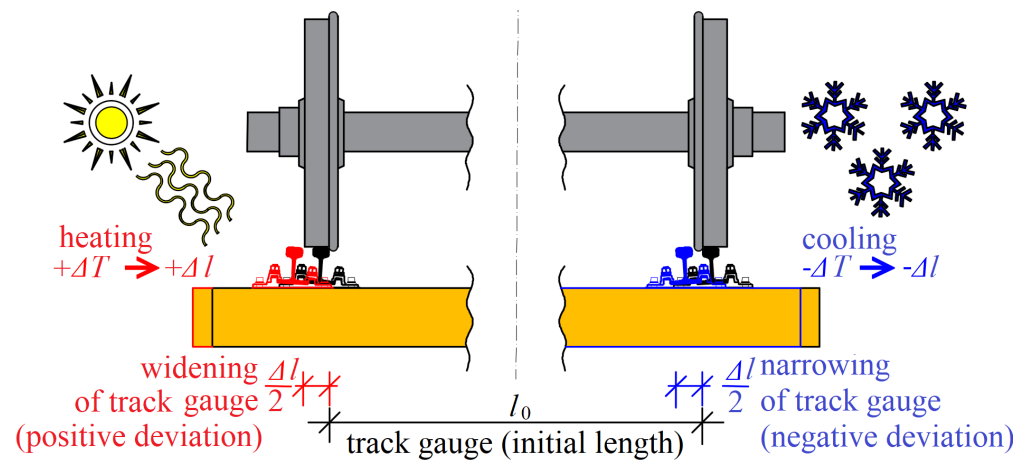

Figure 2. Positive and negative deviations $\Delta l$ of track gauge. Initial length $l_{0}$ changed by $\Delta l$ as the consequence of a change in temperature $\Delta T$ (heating or cooling).

considered as a beam with one prevailing dimension, which is represented with its centreline.

A simplified model of a temperature being equally distributed through the whole sleeper body (a model adopted in this article) states that the change in the length equals to the change of the centreline. As opposed to that, more accurate model described further in the paragraph is being investigated, but for the purpose of this paper, the former, simplified model is sufficient and thus was adopted. As shown in Figure 1, a sleeper in a railway ballast is surrounded with gravel up to its upper surface and thus unequal change in its temperature occurs and deformation may be reduced. The theoretical heat transfer model including parameters of the specific thermal capacity $C$, the thermal conductivity $\lambda$, and the density $\rho$ of the polymer sleeper would describe the sleeper deformation more precisely. The standard track gauge of $1435 \mathrm{~mm}$ is common in majority of the world railways 23. Positive or negative deviation of the track gauge (Figure 2 leads to an excessive wear of wheels and rails, or even derailment. In order to keep maintenance costs in a reasonable range while ensuring the safety of the railway track, it is required to keep the geometrical characteristics of a railway track within permitted values.

In a railway track, deviations of the track geometry parameters, including track gauge, track elevation, track direction, the longitudinal height of rails, etc., are observed. They arise during the track construction phase and also during the operational phase. In the construction phase, allowed parameter deviations of the track are stricter and between maintenance actions, the allowance is less strict.

The permitted deviations listed in the technical standard 736360-2 21] depend on the track gauge, maximal permissible speed and a consideration of the construction or operation phase of a track. The values of a rail gauge deviation in the operational phase are divided into three levels (alert limit, intervention limit, immediate action limit). Taking the alert limit and the permissible speed of up to $230 \mathrm{~km} \cdot \mathrm{h}^{-1}$ into account, the positive allowed deviation of the track gauge is up to $10 \mathrm{~mm}$ and negative up to $3 \mathrm{~mm}$ (Table 1). The negative allowed deviation is always stricter than the positive deviation.

If the sleeper is heated or cooled, the track gauge may theoretically slightly change depending on the temperature change. In order to describe the temperature of a sleeper laid in a railway ballast, a supportive measurement on a track in a municipality of Hostivice was performed. Temperature sensors were placed in the ballast under wooden and plastic sleeper soffit and one sensor was placed one meter above the terrain, all of them collecting data for the period of one year. From the collected data, it was found out that, under local conditions, the sleeper temperature in extreme can vary on the range of about $45^{\circ} \mathrm{C}$. However, typically, the range is lower. In the next part of the article, the temperature of $35^{\circ} \mathrm{C}$ was considered as $\Delta T$. Using the change in the sleeper ambient temperature $\Delta T$ of $35^{\circ} \mathrm{C}$, the normal track gauge of $1435 \mathrm{~mm}$, and the negative deviation of the track gauge $\Delta l$ of $-7 \mathrm{~mm}$ in Eq. (1), the coefficient $\alpha$ is $13.9 \cdot 10^{-5}{ }^{\circ} \mathrm{K}^{-1}$. Additional limit values of the coefficient $\alpha$ for a higher permissible speed are shown in Table 1

A comparable finding from the perspective of an American technical regulation was found in Lampo 23] where the limit value of the coefficient $\alpha$ for polymer sleepers required by American Railway Engineering and Maintenance-of-Way Association (AREMA) is $7.5 \cdot 10^{-5} \mathrm{~K}^{-1}[23]$.

\subsection{DESCRIPTION OF POLYMER SAMPLES SUBJECTED TO THERMAL EXPANSION TEST}

The recycled polymer (REP) selected for the possible sleeper production was subjected to a thermal expansion test. This material is mainly utilized for the production of storage pallets. Details about their application can be found for example in [26]. The used REP is obtained from the polymer waste generated by the general public in households [27]. The polymer waste consists of polyethylene (PE; 65\%), polyethylene terephthalate (PET; $24 \%$ ), polypropylene (PP; $2 \%$ ), polystyrene (PS; $1 \%$ ) and other substances $(8 \%)$ [28. The REP conglomerate is treated 


\begin{tabular}{lccccc}
\hline Permissible speed & $V$ & {$\left[\mathrm{~km} \cdot \mathrm{h}^{-1}\right]$} & $V \leq 120$ & $120<V \leq 160$ & $160<V \leq 230$ \\
\hline Allowed track gauge deviation & $\Delta l$ & {$[\mathrm{~mm}]$} & -7 & -5 & -3 \\
\hline $\begin{array}{l}\text { Limit value of coefficient } \\
\text { of thermal expansion }\end{array}$ & $\alpha$ & {$\left[10^{-5} \cdot \mathrm{K}^{-1}\right]$} & 13.9 & 9.6 & 5.9 \\
\hline
\end{tabular}

TABLE 1. Limit value of thermal expansion coefficient $\alpha$ of sleeper material determined on base of Eq. 1 applying allowed track gauge deviation $\Delta l$ (at alert limit for the track gauge $l$ of $1435 \mathrm{~mm}$ ) and maximal temperature change $\Delta T$ of $35^{\circ} \mathrm{C}$.

\begin{tabular}{lcccc}
\hline Material & REP & REP_C & Ecotrax & Integrico \\
Density $\rho_{a}\left[\mathrm{~kg} \cdot \mathrm{m}^{-3}\right]$ & 940 & 950 & 875 & 1089 \\
\hline
\end{tabular}

TABLE 2. Volumetric mass density $\rho_{a}$ of REP and REP_C and other recycled polymers used in the production of railway sleepers 24,25 .

utilizing the extrusion process under a temperature of $220^{\circ} \mathrm{C}$ and the pressure of $100 \mathrm{MPa}$.

In order to reduce the thermal expansion of the REP, a reinforcement made of glass fibres was applied into the REP conglomerate. Chopped glass fibres [29] with a length of $12 \mathrm{~mm}$ arranged multi-directionally were applied. The selection criterion of the fibres' length was provided by the production technology (the narrowest spot in the extruder was $15 \mathrm{~mm}$ ), and the fibres' material was chosen in relation to the wear and tear of an extruder by an abrasive material. The choice of fibres weight concentration was based on:

- literature research - the recommendation is to add the fibres in the volumetric concentration of at least $15 \%$ 30,

- experimental development of polymer railway sleepers in 31] where the volumetric concentration of $12.5 \%$ was used,

- experience with REP resulting in the minimum weight concentration of $12 \%$ of glass fibres 28 .

The fibres weight concentration was chosen at $15 \%$. This composite material composed of recycled polymer reinforced with glass fibres was labelled as REP_C. Both materials including REP and REP_C were subjected to the thermal expansion test. The specimens made of REP and REP_C were of a prismatic shape with the dimensions of $160 \times 40 \times 40 \mathrm{~mm}$. There was a total of 18 specimens prepared and separated into 2 groups (REP and REP_C) both consisting of 9 specimens.

Consequently, the volumetric mass density $\rho_{a}$ of REP and REP_C was determined in order to describe these materials. The density $\rho_{a}$ was calculated on the basis of the weight and with the dimensions measured with a calliper. The density $\rho_{a}$ was identified within the natural moisture of polymers. The laboratory determined density $\rho_{a}$ of REP and REP_C is shown in Table 2. For a better insight, the density $\rho_{a}$ of different recycled polymers commonly used in the production of railway sleepers is also reported here.
The density of REP and REP_C was comparable, since the matrix material of REP and REP_C is based on the same mixture. The small difference between them is attributed to the content of glass fibres in REP_C. Other types of recycled polymers, mentioned in Table 2 resulted in approximately $10 \%$ difference in the density.

\subsection{Methodology}

The coefficient of thermal expansion, $\alpha$, was determined based on a procedure specified in standard CSN 640528 [32. In the standard, the specimen is described as a polymer body with the required minimal length of $50 \mathrm{~mm}$ with a perpendicular or circular cross section. The test is required to be done with a minimal number of three specimens.

The length of the REP and REP_C specimens was determined with a calibrated Mitutoyo Absolute Digimatic indicator with a precision of $\pm 0.001 \mathrm{~mm}$. The indicator was mounted in a metal dilatometer intended for the purpose of the thermal expansion measurement. The specimens and the test set-up is shown in Figure 3

The specimen length was always measured after a conditioning period at a certain temperature level. For heating, a calibrated electric oven KCW 100 with a digital thermometer was used. Freezing the specimens was done with a calibrated Cooper climate chamber equipped with a digital thermometer.

The first step consisted of measuring the initial length three times at a default temperature of $+20^{\circ} \mathrm{C}$. The specimens were conditioned in the electric oven at the default temperature for 12 hours. Then, the specimens were conditioned in two identical temperature cycles. The temperature cycles are shown in Figure 4

One temperature cycle, in which the specimens were firstly cooled and then heated, consisted of the following temperature steps:

- cooling to $0,-10,-20,-10,0{ }^{\circ} \mathrm{C}$ and then 

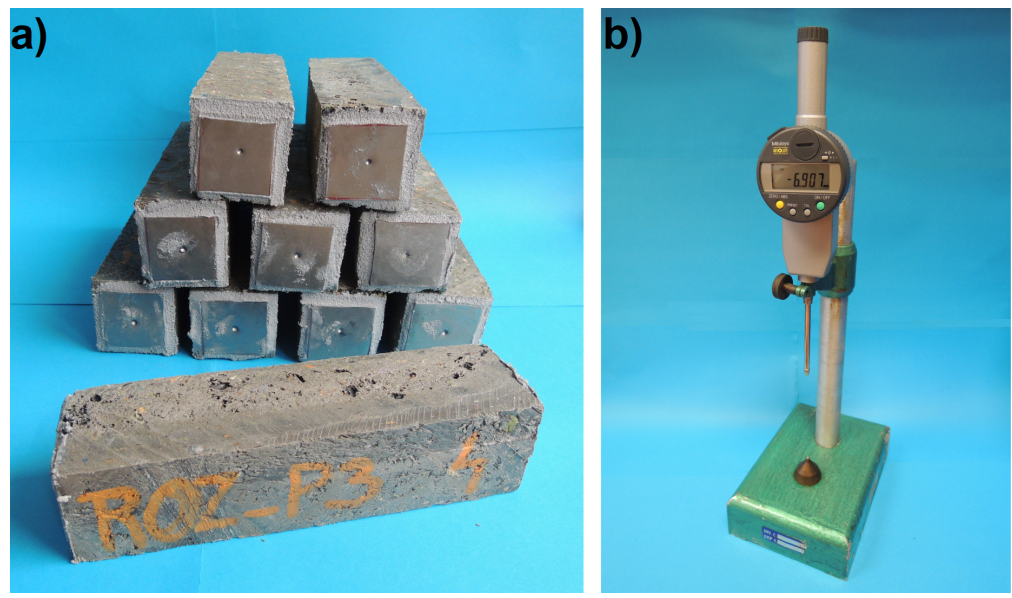

FiguRE 3. Determination of the thermal expansion: a) polymer specimens made of REP, b) the dilatometer with the displacement sensor.

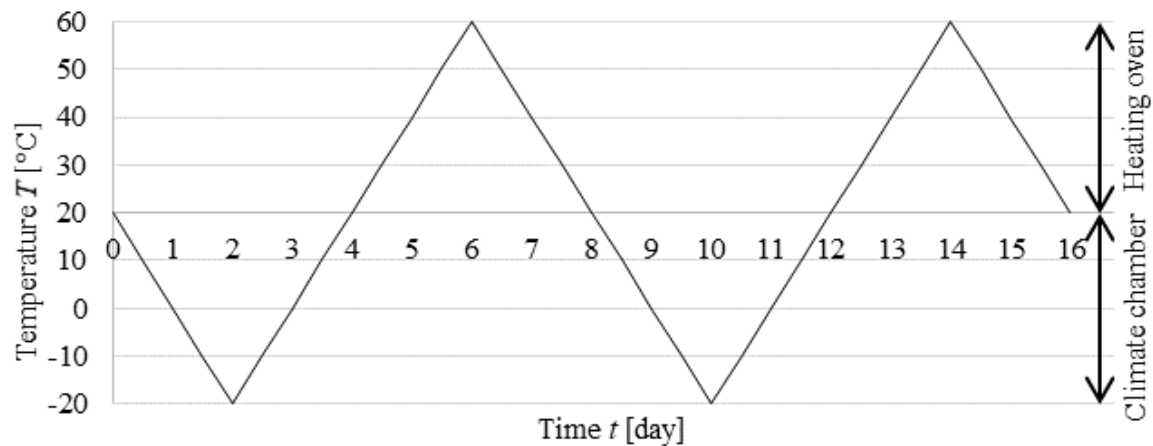

FIGURE 4. Illustration of thermal loading function for polymer specimens.

- heating to $+10,+20,+30,+40,+50,+60,+50$, $+40,+30^{\circ} \mathrm{C}$ and finally back to the default temperature step of $+20^{\circ} \mathrm{C}$.

The length of each specimen was measured at every single temperature step. Conditioning at every temperature level took 12 hours. According to temperature cycles and steps, each specimen's length was measured more than 30 times.

\section{Results AND Discussion}

In this part of the paper, data collected from the laboratory test as well as the evaluation of the strain $\epsilon_{t}$ related to the change in temperature $\Delta T$ and coefficient $\alpha$ are processed. In the selected range of temperatures, the linearity of the thermal expansion coefficient $\alpha$ for REP and REP_C was estimated.

\subsection{Relative DEFormation}

The development of relative deformation or, in other words strain, $\epsilon_{t}=\left(l_{1}-l_{0}\right) / l_{0}$, of the specimens made of the REP and REP_C subjected to two temperature test cycles, is presented in Figures 5, 6. The temperature cycles ranging between -20 to $+60{ }^{\circ} \mathrm{C}$ are expressed as the temperature change $\Delta T$ relatively to $+20^{\circ} \mathrm{C}$, which was the initial temperature of specimens. Therefore, the temperature change $\Delta T$ presented in graphs on the horizontal axis is between -40 and $+40^{\circ} \mathrm{C}$.

There was a consistency in the behaviour of the REP and REP_C specimens, however, the REP_C curves were relatively scattered, which can be attributed to an uneven distribution of the dispersed glass fibre reinforcement.

The polymer reinforced with glass fibres achieved a visibly lower relative deformation $\epsilon_{t}$. The higher the change in the temperature $\Delta T$ is, the higher difference in relative deformation $\epsilon_{t}$ between REP and REP_C may be expected. The significant difference of about $30 \%$ can be found at the temperature change $\Delta T$ of $+40^{\circ} \mathrm{C}$, which is a consequence of the fibre reinforcement effect.

Once the test cycles were finished, both materials exhibited contraction. The residual deformation $\epsilon_{t}$ after two temperature test cycles of REP was -3.14 . $10^{-4}$ and of REP_C was $-3.56 \cdot 10^{-3}$.

The arithmetic mean and the $95 \%$ probability interval of the relative deformation $\epsilon_{t}$ for both polymer types were calculated. The plot showing the relative deformation $\epsilon_{t}$ in Figure 7 represents 8 REP and 9 REP_C specimens. For the data processing, the assumption of the normal (Gaussian) probability distribution was assumed. 


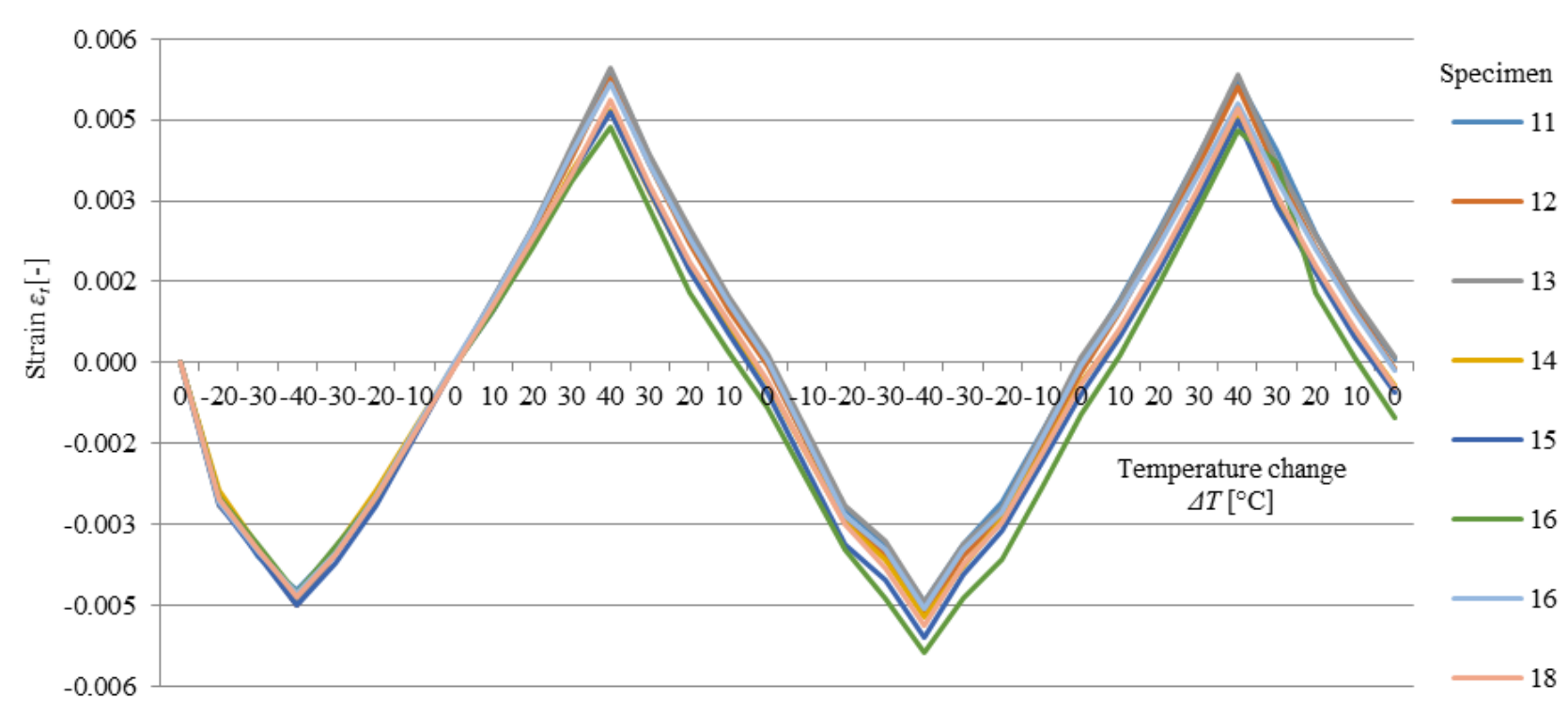

FiguRE 5. Relative deformation $\epsilon_{t}$ of REP in the function of temperature change $\Delta T$.

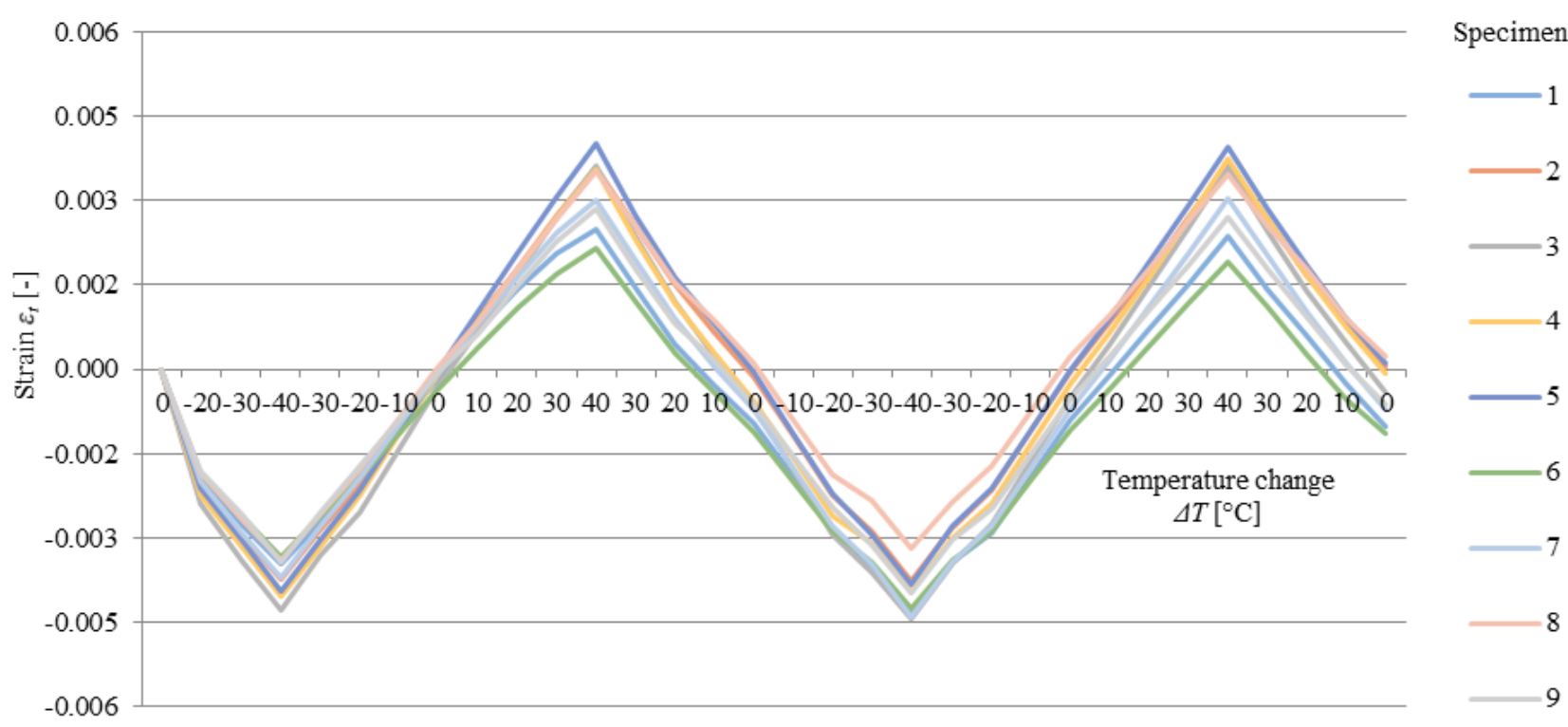

Figure 6. Relative deformation $\epsilon_{t}$ of REP_C in the function of temperature change $\Delta T$.

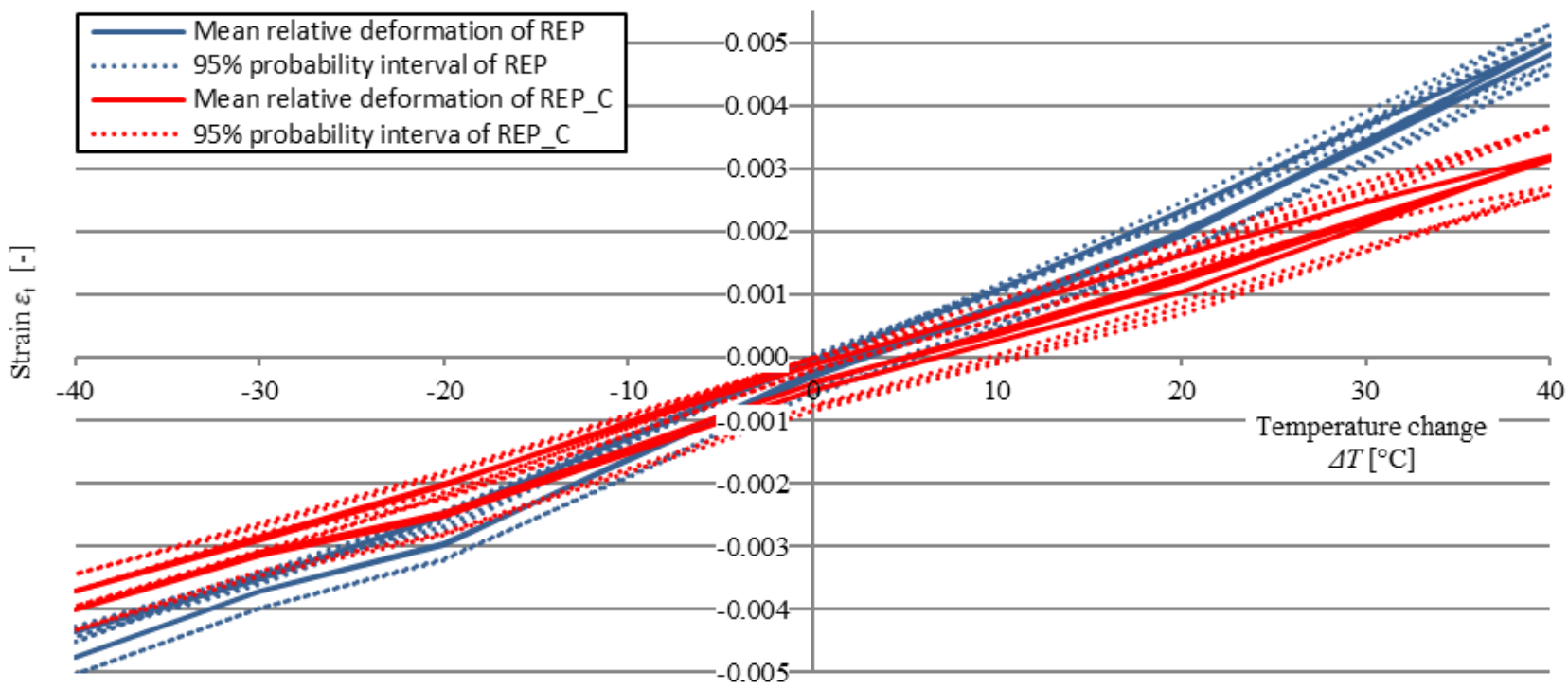

FIGURE 7. Hysteresis loops of mean values and $95 \%$ probability of strain $\epsilon_{t}$ for REP and REP_C samples. 


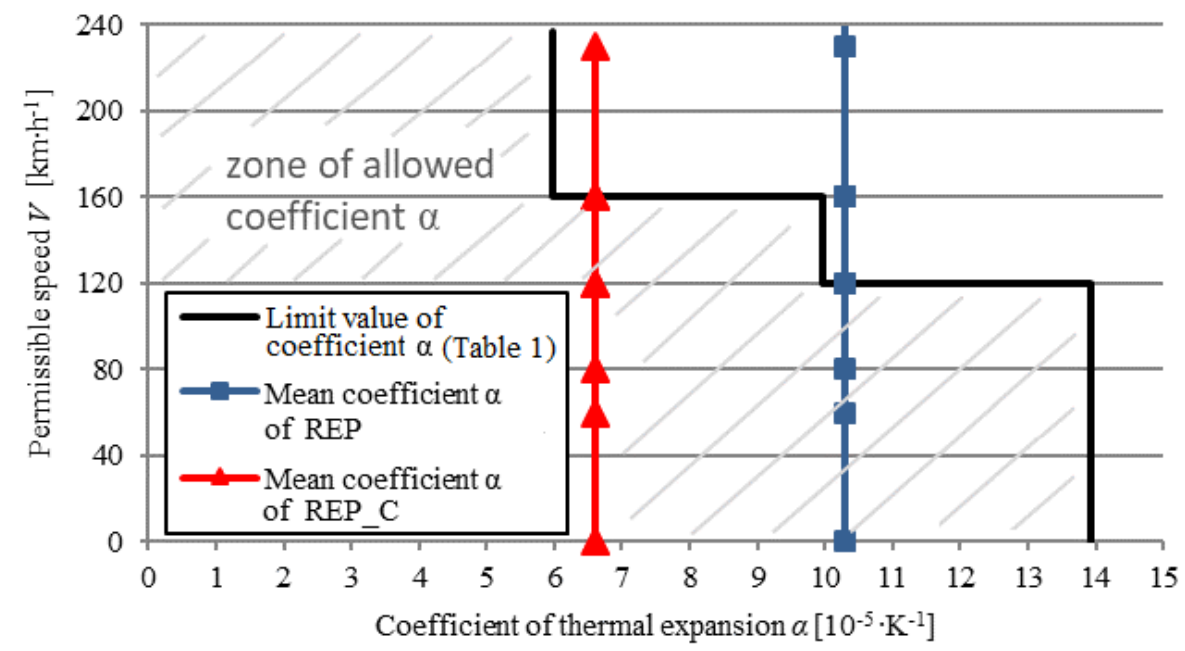

FiguRE 8. Limit value of linear thermal expansion coefficient $\alpha$ of sleeper materials based on allowed deviation of track gauge and permissible speed $V$ and coefficient $\alpha$ of REP and REP_C.

\begin{tabular}{lccccc}
\hline Recycled polymer & REP & REP_C & IntegriTies & Ecotrax & TieTek \\
Coefficient $\alpha\left[10^{-5} \cdot K^{-1}\right]$ & $10.3 \pm 2.2$ & $6.6 \pm 2.6$ & 4.0 & 7.4 & 7.5 \\
\hline
\end{tabular}

TABlE 3. Summary of thermal expansion coefficient $\alpha$ of REP and REP_C and polymer sleeper products [24, 26, 33].

Based on the comparison of materials in the graph above, the content of glass fibres in $\mathrm{REP} \_\mathrm{C}$ led to the reduction of the strain $\epsilon_{t}$ up to $25 \%$ in relation to the REP without glass fibre reinforcement.

\subsection{CoEfFiCient of LineAR THERMAL EXPANSION}

The coefficient of thermal expansion $\alpha$ of REP and REP_C was expressed on the base of Eq. 1 from the positive part of the relative deformation in Figure 7 For the calculation of the coefficient $\alpha$, the second temperature cycle was chosen, because it was assumed that the material became stable. The coefficient $\alpha$ of $\mathrm{REP}$ is $10.3 \pm 2.2$ and of REP_C is $6.6 \pm 2.6 \mathrm{~K}^{-1} \cdot 10^{-5}$. These results correlate well with reference polymer sleeper products referred in Table 3 .

The difference in the coefficient $\alpha$ between REP_C with glass fibres and REP without glass fibres correlates with the material mass density $\rho_{a}$ of REP and REP_C, presented in Table 2 When comparing REP _ C with other materials, REP_C achieved similar results to other materials used in the production of railway sleepers.

Assuming the formulated recommended value of the coefficient of thermal expansion (Table 1) shown in a graph in Figure 8, the conclusion about REP and REP_C can be said.

The conclusions about the application of REP and $\mathrm{REP} \_\mathrm{C}$ in the production of railway sleepers arose from the maximal recommended values of coefficients $\alpha$. The thermal expansion of REP reaches the maximal recommended value for the material of railway sleepers for the railway lines with a permissible speed up $120 \mathrm{~km} \cdot \mathrm{h}^{-1}$. In addition, REP significantly ex- ceeds the AREMA recommendation for the coefficient $\alpha$ of $7.5 \cdot 10^{-5} \mathrm{~K}^{-1} 23$. The thermal expansion of REP_C is satisfactory for railway lines with a permissible speed up to $160 \mathrm{~km} \cdot \mathrm{h}^{-1}$. Other polymers mentioned in Table 3 are also suitable in the same extent as REP_C, or slightly better.

\section{Conclusions}

The influence of the thermal expansion of polymers in the application of railway sleepers from the perspective of a track gauge stability was discussed. It is crucial to mention that the coefficient $\alpha$ of a sleeper material should be as low as possible in order to maximize the track gauge stability, which is permanently deteriorated with operations of railway traffic. Within certain design parameters of a railway track and assumptions about possible temperature range of the permanent way, the simplified calculations of an admissible thermal expansion were made with respect to common design procedures and dimensions. As the main finding of this article, limit values of the thermal expansion coefficient $\alpha$ for the sleeper material were obtained. The thermal expansion of polymers used for the production of plastic sleepers plays a minor role when assessing the material suitability for a possible production but it should be considered.

The investigated recycled polymer REP exhibited a comparable thermal expansion to other polymers used in the production of railway sleepers. Moreover, a glass fibre reinforcement was used to assess its influence on the behaviour of the recycled polymer with respect to a changing temperature. The presence of the reinforcement resulted in lower values of thermal expansion and the use of the reinforcement was justi- 
fied. From the thermal expansion point of view, the results indicate the suitability of the recycled polymers for the production of railway sleepers.

It is recommended to perform the complex thermaltechnical calculation of a railway sleeper laid in a railway ballast material in a further research. This calculation should provide more precise information about heat transfer and consequent thermal expansion of the sleeper with respect to the track gauge stability issue.

\section{ACKNOWLEDGEMENTS}

This paper was prepared with the support from the Grant Agency of the Czech Technical University in Prague, the Czech Republic, grant No. SGS 161 - 1611579A137.

\section{REFERENCES}

[1] C. Bonnett. Practical railway engineering. Imperial College Press, London, 1996.

[2] A. Manalo, T. Aravinthan, W. Karunasena, A. Ticoalu. A review of alternative materials for replacing existing timber sleepers. Composite Structures 92(3):603 - 611, 2010. DOI:10.1016/j.compstruct.2009.08.046.

[3] W. Ferdous, A. Manalo. Failures of mainline railway sleepers and suggested remedies - Review of current practice. Engineering Failure Analysis 44:17 - 35, 2014. DOI:10.1016/j.engfailanal.2014.04.020.

[4] S. Yella, M. Dougherty, N. K. Gupta. Condition monitoring of wooden railway sleepers. Transportation Research Part C: Emerging Technologies 17(1):38 - 55, 2009. DOI:10.1016/j.trc.2008.06.002.

[5] T. Thierfelder, E. Sandström. The creosote content of used railway crossties as compared with European stipulations for hazardous waste. Science of The Total Environment 402(1):106 - 112, 2008. DOI:10.1016/j.scitotenv.2008.04.035

[6] International Union of Railways. Sustainable wooden railways sleepers. UIC report, UIC, Paris, 2013.

[7] C. González-Nicieza, M. Álvarez Fernández, A. Menéndez-Díaz, et al. Failure analysis of concrete sleepers in heavy haul railway tracks. Engineering Failure Analysis 15(1):90 - 117, 2008. DOI:10.1016/j.engfailanal.2006.11.021.

[8] V. Lojda, J. Jeřábek, L. Horníček. Utilizing a pressure paper for the determination of contact parameters between aggregate and a railway sleeper. In 19th International Multidisciplinary Scientific GeoConference SGEM 2019, pp. 565 - 572. Albena, 2019. DOI:10.5593/sgem2019/1.2/S02.072

[9] D. Feldman, G. Akovali. Polymers in Construction: Past and Future Trends. Rapra Technology Limited, Shrewsbury, 2005.

[10] M. Lidmila. New perspectives in the use of recycled materials in railway engineering. In Sustainable infrastructure. Prague, 2006.

[11] A. Belkom. Recycled plastic railway sleepers. Analysis and comparison of sleeper parameters and the influence on track stiffness and performance. In Railway Engineering 2015. Edinburgh, 2015.
[12] L. Hudeček, D. Cihlářová. The problems of railways in the undermined areas. In 15th International Multidisciplinary Scientific GeoConference SGEM 2015. Albena, 2015. DOI:10.5593/SGEM2015/B13/S3.093.

[13] W. Ferdous, A. Khennane, O. Kayali. Hybrid frpconcrete railway sleeper. In 6 th International Conference on Advanced Composites in Construction. Belfast, 2013.

[14] W. Ferdous, A. Manalo, G. V. Erp, et al. Evaluation of an innovative composite railway sleeper for a narrow-gauge track under static load. Journal of Composites for Construction 22(2):04017050, 2018. DOI:10.1061/(ASCE)CC.1943-5614.0000833.

[15] W. Ferdous, A. Manalo, G. V. Erp, et al. Composite railway sleepers - Recent developments, challenges and future prospects. Composite Structures 134:158 - 168, 2015. DOI:10.1016/j.compstruct.2015.08.058

[16] V. Lojda. Set of laboratory tests for composite sleepers. In Young Scientist 2015. Jasná, 2015.

[17] V. Lojda, A. Belkom. Fire safety of polymer sleepers in terms of fire propagation. In 19th International Multidisciplinary Scientific GeoConference SGEM 2019, pp. 247 - 256. Albena, 2019. DOI:10.5593/sgem2019/1.2/S02.032.

[18] U. Alkan, Y. Özcanll, V. Alekberov. Effect of temperature and time on mechanical and electrical properties of HDPE/glass fiber composites. Fibers and Polymers 14(1):115 - 120, 2013. DOI:10.1007/s12221-013-0115-6.

[19] L. Mascia. Polymers in industry from A-Z: a concise encyclopedia. Wiley-VCH, Weinheim, 2012.

[20] R. Taylor, et al. Thermal Expansion of Solids. ASM International, Russel Township, 1998.

[21] CSN 736360-2: Geometrical characteristics of railway tracks - Part 2: Construction and acceptance, service and maintenance. Standard, Czech Standardization Agency, 2009.

[22] C. Esveld. Thermal Expansion of Solids. MRT-Productions, Delft, 2001.

[23] R. Lampo. Summary of current state of practice for composite crossties. In International crosstie and fastening system symposium. Champaign-Urbana, 2014.

[24] Sicut Composite Railway Sleeper, Technical sheet. http://www.sicut.co.uk/. Accessed: 23 June 2019.

[25] IntegriTies ${ }^{\mathrm{TM}}$ technical specifications integrico composites. http://integrico.com/products/ technical-specifications/ Accessed: 23 June 2019.

[26] V. Lojda. Effect of thermal expansion in the development of recycled plastic railway sleeper. In Trends and Innovations in Transport Infrastructure, pp. 162-167. Prague, 2016.

[27] CSN 640003: Terms relating to the valorisation of plastic waste. Standard, Czech Standardization Agency, 2006.

[28] Analysis of material for the company Stabilplastik. Report, Remiva, Chropyně, 2011.

[29] Owens Corning Anti-crak HP 67/36, Technical sheet. http://www.ocvreinforcements.com/, 2011. Accessed: 27 June 2019. 
[30] G. W. Ehrenstein. Polymeric composite materials. Scientia, 2011.

[31] R. Chattree, S. Manoharan, P. Satyanarayana. Composite sleepers for bridges: progress till date and road ahead. Indian Railways Institute of Civil Engineering, Pune, 2010.
[32] CSN 640528: Plastics. Determination of coefficient of linear thermal expansion of plastics. Standard, Czech Standardization Agency, 1993.

[33] TieTek Composite Railroad and Transit Rail Crossties, Technical sheet. http://www.tietek.net/specsheets.asp Accessed: 23 June 2019. 